\title{
FAILURE OF AN EARTHEN DAM AND ITS POSSIBLE STRENGTHENING METHODS
}

\author{
Bhuddarak CHARATPANGOON¹, Junji KIYONO², Aiko FURUKAWA ${ }^{3}$ \\ and Chayanon HANSAPINYO 4 \\ ${ }^{1}$ Member of JSCE, Assistant Professor, Dept. of Urban Management, Kyoto University \\ (Kyoto daigaku-katsura, Nishikyo-ku, Kyoto 615-8530, Japan) \\ E-mail:bhuddarak@hotmail.com \\ ${ }^{2}$ Member of JSCE, Professor, Graduate School of Global Environmental Studies, Kyoto University \\ (Kyoto daigaku-katsura, Nishikyo-ku, Kyoto 615-8530, Japan) \\ E-mail: kiyono.junji.5x@kyoto-u.ac.jp \\ ${ }^{3}$ Member of JSCE, Associate Professor, Graduate School of Global Environmental Studies, Kyoto University \\ (Kyoto daigaku-katsura, Nishikyo-ku, Kyoto 615-8530, Japan) \\ E-mail: furukawa.aiko.3w@kyoto-u.ac.jp \\ ${ }^{4}$ Assistant Professor, Dept. of Civil Engineering, Chiang Mai University \\ (239 Huay Kaew Road, Muang District, Chiang Mai 50200, Thailand) \\ E-mail: chayanon@eng.cmu.ac.th
}

\begin{abstract}
This study aimed to examine the failure mechanisms of the Fujinuma Dam and introduce possible seismic strengthening methods for earth dams. The study consists of field and laboratory experiments and a numerical simulation of the dam. Laboratory experiments were conducted to acquire necessary information. For the seismic analysis, a coupled solid-fluid finite element formulation was applied. The observed and simulated motions of the 2011 Tohoku Earthquake were used as input motions. Frequency and dynamic analyses were performed thereafter; dam behavior and possible failure mechanisms are presented. In addition, the seismic strengthening techniques of the studied dam are introduced and discussed.
\end{abstract}

Key Words : earthen dam, dam failure, seismic safety, finite element, strengthening method

\section{INTRODUCTION}

An earth dam is a common type of water retaining structure that serves the community in many ways, such as flood control, use as a recreation site, water supply, and irrigation. Earth dams are cost effective; their construction is straightforward because the necessary building material may be found directly on the site. These reasons have caused earth dams to become popular and widely constructed throughout the globe. Therefore, public safety is of vital importance, especially for those who live downstream from an earth dam. So far, there are a lot of existing dams that were constructed a long time ago, some of which were designed without any consideration of earthquake effects or in an otherwise inappropriate way. Accordingly, a number of existing dams may be at risk of failure following seismic excitation. The seismic safety of existing dams is therefore crucial and urgent.
Following the devastating Tohoku earthquake in Japan on March 11, 2011, the Fujinuma Dam, which serves as a water supply for irrigation purposes, failed. The failure caused a flood that damaged the downstream area. Therefore, to assure dam safety, proper evaluation of such dams is crucial. Accordingly, the failure of the Fujinuma Dam can be regarded as a fruitful resource that allows for a better understanding of dam failure mechanisms and for the acquisition of useful information about the seismic safety of earth dams.

Recently, as advanced computational techniques in geotechnics have been introduced, it has become beneficial for researchers ${ }^{1-4)}$ to analyze the seismic behavior of dams by using these techniques. Consequently, much research has been conducted on the seismic safety of existing earth dams. All of these methods have been applied to evaluate the safety of earth dams. The importance of such research is not only to examine the behavior of a dam or the level of 
damage it can sustain but also to preserve it against future earthquakes.

Because the field of earthquake engineering has been well established, concerned groups are now raising awareness about the safety of their structures, including dams. Therefore, many researchers ${ }^{5)-7)}$ have proposed seismic strengthening methods for embankment dams, such as adding downstream berms, increasing freeboard, enlarging a dam, replacing improper soil, enhancing the drainage system, establishing an emergency action plan, or even considering taking no action. Suggestions and discussions about each method were presented. Eventually, the most proper technique has been recommended along with a comparison with other techniques.

For strengthening soil structure, geogrid reinforcement is now becoming popular due to its effectiveness. Previous research ${ }^{8-9)}$ has been conducted to study the geogrid reinforced embankment. The results demonstrated that the geogrid could better improve the stability of the embankment than other conventional methods.

This study aims to gain insight into the behavior of the Fujinuma Dam during the time of the earthquake by using the finite element (FE) method. Both observed and simulated motions were used to determine the response of the dam during the excitation. The soil behavior of the dam materials is described by using the Mohr-Coulomb soil model available in the Plaxis FE code. ${ }^{10)}$ Dynamic analyses of the model are conducted, and the overall dam behaviors are presented. Discussions and comparisons between the simulation results and existing facts are expressed. Also, seismic strengthening techniques are introduced as alternative methods for improving the seismic safety of an earth dam, and the results of using such methods are discussed.

Table 1 Soil samples

\begin{tabular}{|c|c|}
\hline Test & $\begin{array}{c}\text { Number of } \\
\text { samples }\end{array}$ \\
\hline Permeability & 1 \\
\hline Triaxial CU & 12 \\
\hline & 4 \\
\hline - $\quad$ Middle & 4 \\
\hline - $\quad$ Upper & 4 \\
\hline Total & 13 \\
\hline
\end{tabular}

\section{DAM SITE AND INPUT MOTIONS}

\section{(1) Fujinuma Dam and input motions}

The Fujinuma Dam was an earth-filled embankment dam near the city of Sukagawa in the Fukushima prefecture in Japan. It was established on the Ebana River, a tributary of the Abukuma River, 16 $\mathrm{km}$ west of the city office of Sukagawa $\left(37^{\circ} 18^{\prime}\right.$ $\left.07^{\prime \prime} \mathrm{N}, 140^{\circ} 11^{\prime} 41^{\prime \prime} \mathrm{E}\right)$. The purpose of the dam was water supply for irrigation. The typical cross section of the main dam is shown in Fig.2. The dam was an embankment type, $18.5 \mathrm{~m}$ high and $133 \mathrm{~m}$ long with a structural volume of $99,000 \mathrm{~m}^{3}$ and a crest width of $6 \mathrm{~m}$. The dam was at the head of an 8.8 $\mathrm{km}^{2}$ drainage area, giving it a reservoir capacity of $1,504,000 \mathrm{~m}^{3} .{ }^{11)}$

\section{(2) Dam materials and their properties}

In this study, laboratory experiments have been conducted to extract the necessary information for studying the dam failure. Facts and discussions about dam materials obtained from laboratory experiments are presented and discussed. To facilitate the numerical simulation and study of the dam failure, thirteen undisturbed cylinder samples were collected at the site. These samples can be defined based on their origin and testing purpose, as shown in Table 1.

\section{a) Sieve analysis}

The sieve number applied in this study was in the range of 4-200. The results show that both the middle and bottom layer consist of a high percentage of fine particle sizes (Fig.1). Furthermore, about $30-40 \%$ of the particles in these layers are smaller than $0.1 \mathrm{~mm}$, whereas the upper part is shown to consist mainly of sandy materials. The boundaries for potentially liquefiable soil (b-b) and boundaries for most liquefiable soil (a-a) are shown in Fig.1. ${ }^{12)}$ Accordingly, it can be determined that the bottom

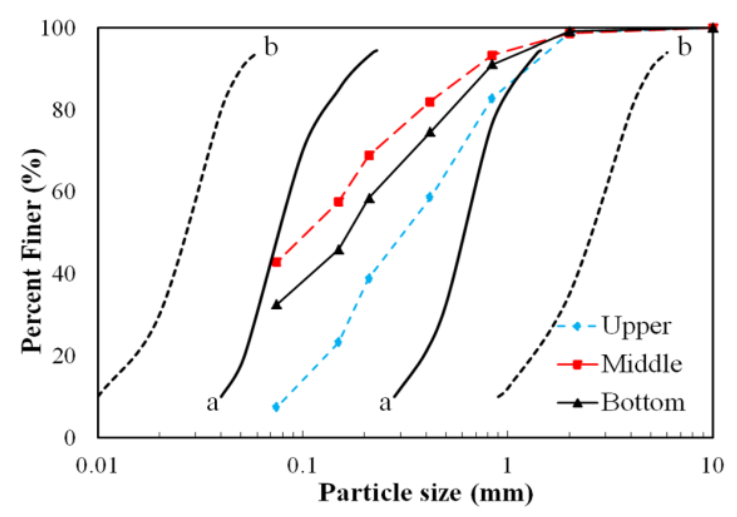

Fig.1 Sieve analysis 
Table 2 Material properties

\begin{tabular}{|c|c|c|c|c|c|c|c|c|c|}
\hline Materials & Layer & $\begin{array}{c}\gamma_{d r y} \\
\left(\mathrm{kN} / \mathrm{m}^{3}\right)\end{array}$ & $\begin{array}{c}\gamma_{s a t} \\
\left(\mathrm{kN} / \mathrm{m}^{3}\right)\end{array}$ & $\begin{array}{c}k_{y} \cong k_{x} / 4 \\
(\mu \mathrm{m} / \mathrm{s})\end{array}$ & $\begin{array}{c}E \\
(\mathrm{MPa}) \\
\end{array}$ & $\begin{array}{l}K_{w} / n \\
(\mathrm{GPa})\end{array}$ & $v$ & $\begin{array}{c}c^{\prime} \\
(\mathrm{kPa})\end{array}$ & $\begin{array}{c}\phi^{\prime} \\
(\mathrm{deg}) \\
\end{array}$ \\
\hline \multirow[t]{3}{*}{ Dam body } & Bottom & 16.0 & 18.0 & 0.55 & 50.0 & 1.87 & 0.30 & 18.4 & 31.0 \\
\hline & Middle & 14.0 & 16.0 & 0.55 & 30.0 & 1.12 & 0.30 & 7.80 & 32.0 \\
\hline & Upper & 16.0 & 18.0 & 0.55 & 17.5 & 0.65 & 0.30 & 0.00 & 37.0 \\
\hline Foundation & & 30.0 & - & - & 300 & - & 0.20 & - & - \\
\hline \multirow{2}{*}{ Geogrid } & \multicolumn{3}{|c|}{ Axial stiffness, EA (MN/m) } & \multicolumn{4}{|c|}{ Tensile strength $(\mathrm{kN} / \mathrm{m})$} & & \\
\hline & \multicolumn{3}{|c|}{10.0} & \multicolumn{3}{|c|}{200} & & & \\
\hline
\end{tabular}

and middle portions were not vulnerable to liquefaction because their distribution curves show high percentages of fine particles. Information on the distribution of fine particles was obtained from the study of Tanaka et al. ${ }^{13)}$ According to their study and laboratory experiment, the clay content (particles smaller than $2 \mu \mathrm{m}$ ) of the middle and bottom portions are about $30 \%$ and $10 \%$, respectively. Andrews and Martin ${ }^{14)}$ stated that soils are susceptible to liquefaction if they contain particles less than $10 \%$ finer than $2 \mu \mathrm{m}$ and a liquid limit less than 32; soils are not susceptible to liquefaction if they contain particles greater or equal to $10 \%$ finer than $2 \mu \mathrm{m}$ and a liquid limit greater or equal to 32 . Accordingly, both the middle and bottom are not susceptible to liquefaction. Moreover, from the site investigation, there is no obvious evidence-such as sand boils at the site - to confirm the occurrence of the liquefaction.

\section{b) Triaxial test}

In order to get material properties for conducting FE analysis of the dam, the consolidated-undrained triaxial test was applied in this study. The triaxial test results are presented in Table 2. The dry $\left(\gamma_{d r y}\right)$ and saturated unit weight $\left(\gamma_{\text {sat }}\right)$ defined the mass for the element located in dry and saturated areas, respectively. Permeability or hydraulic conductivity $k$ described the fluid movement through porous media. In the elastic range, the modulus of elasticity $E$ indi- cated the relationship between stress and strain within the elastic region, and Poisson's ratio $v$ provided information on the effect of the load in one direction in relation to the deformation in other directions. The shear strength parameters cohesion $c$ and friction angle $\phi$ were used to form the failure surface for this model. Finally, by considering slight compressibility of water, the rate of excess pore pressure was defined as $K w / n$, in which $K w$ is the bulk modulus of water and $n$ is the soil porosity. Geogrid properties were obtained from previous researchers. ${ }^{8-9)}$ The geogrid parameters were defined only in terms of axial rigidity, EA, and tensile strength.

\section{(3) Input motions}

In regards to the magnitude $9.0(\mathrm{Mw})$ undersea megathrust earthquake off the Pacific coast of Japan (JMA), ${ }^{15)}$ which occurred on March 11, 2011, two motions were selected for use as input motions in this study. The first one is the ground motion record obtained from Station FKS017 located $15 \mathrm{~km}$ away from the site in Sukagawa, Fukushima, Japan, which was provided by the Kyoshin network operated by the National Research Institute for Earth Science and Disaster Prevention. ${ }^{16)}$ Another motion was obtained from Hata et al. ${ }^{17)}$ They estimated the simulated ground motion for the dam site by microtremor ob-

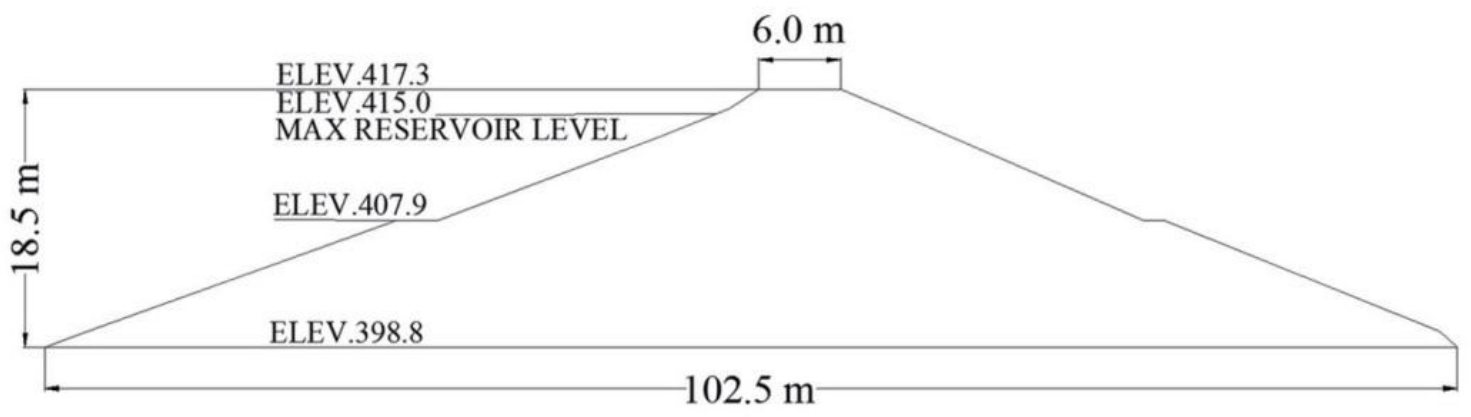

Fig.2 Typical cross section of the main dam 
servation by using the site effect substitution method. The maximum peak ground acceleration was 4.198 and $4.25 \mathrm{~m} / \mathrm{s}^{2}$ for the observed and simulated motions, respectively (Fig. 3a and 3b). The spectra of both motions are shown in Fig. 3c and 3d. The 2.96 $\mathrm{Hz}$, respectively. The smoothed spectra of both motions were also introduced by applying a 50-period moving average (50 per. Mov. Avg.).
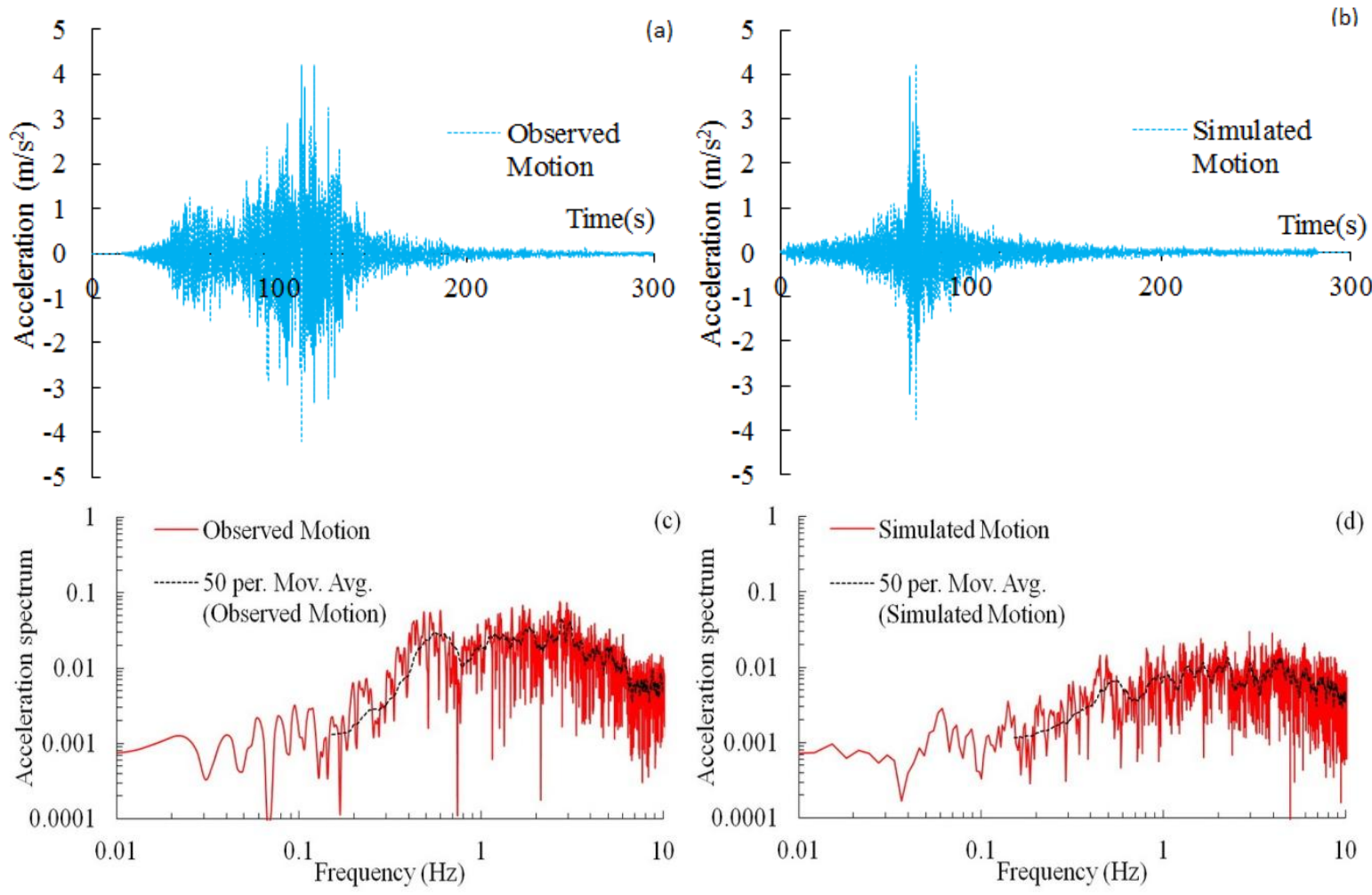

Fig.3 Input motions (a) observed motion at FKS017 $15 \mathrm{~km}$ from the dam site (b) simulated motion at the dam site (c) spectrum of observed motion (d) spectrum of simulated motion

\section{METHODOLOGY}

\section{(1) FE model}

In this study, the numerical simulations are carried out using finite element analysis. The two-dimensional plane strain element derived from the coupled solid-fluid formulation, or $\mathrm{u}-\mathrm{p}$ formulation, was applied to taking into account the interaction between soil matrix and pore pressure. In dynamic analysis, to determine the cause of the dam failure, the numerical model of the original cross section of the dam was used (hereafter, actual dam model, in Fig. 4). Also, another model was proposed based on the remaining sections of the main dam (hereafter, remains dam model, in Fig. 5) to compare its fundamental frequency with the results obtained from microtremor observation. The foundation was modeled by extending a $10-\mathrm{m}$-thick layer $100 \mathrm{~m}$ either side of the center. The boundary conditions were restrained in the horizontal and vertical directions at the bottom of the model. For both edges, the boundary conditions were fixed only in the lateral direction and were free in the vertical direction. The dam's body was classified into three portions: upper, middle, and bottom.

Dynamic analysis was performed using the Plaxis FE code.10) Rayleigh damping was assumed in the dynamic analysis by considering 5\% damping in the frequency range of $1.64-2.45 \mathrm{~Hz}$.

Three strengthening methods were proposed and analyzed to find out the proper solutions for the studied dam. In dynamic analysis of these strengthening models, only simulated motion was used as input motion because it is quite difficult to compare each method when using the vigorous observed motion. The strengthening techniques presented in this study are as follows: 1) add a berm to the downstream slope by the half of the dam's height (hereafter, S1). The S1 model is shown in Fig.6. For S1, the amount of the added soil volume was about $20 \%$ of the actual dam volume and its properties were considered to be the same as the middle soil layer used in the original dam body. 2) Enlarge the dam by increasing dam height and adding a downstream 


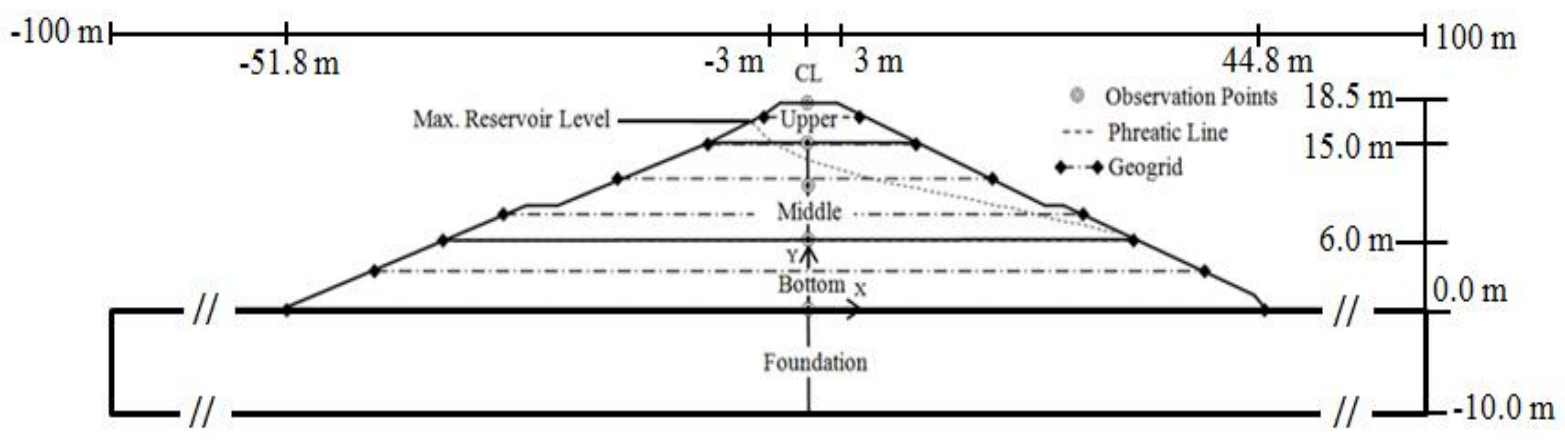

Fig.4 Actual dam model and Strengthening model 3, S3

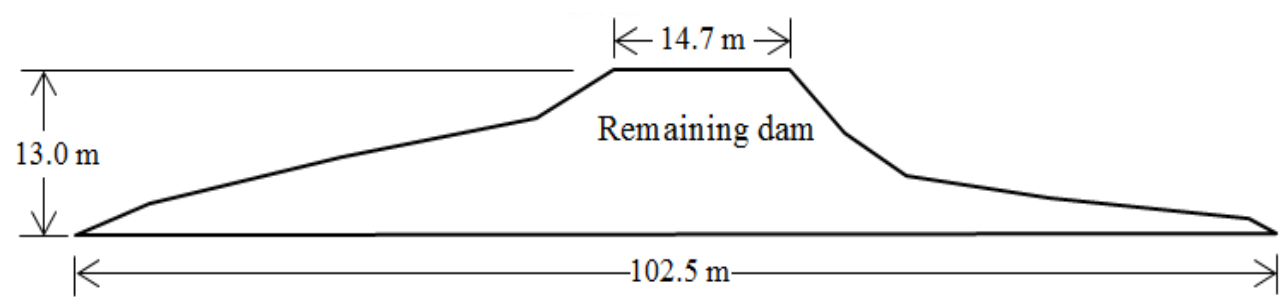

Fig.5 Remains dam model

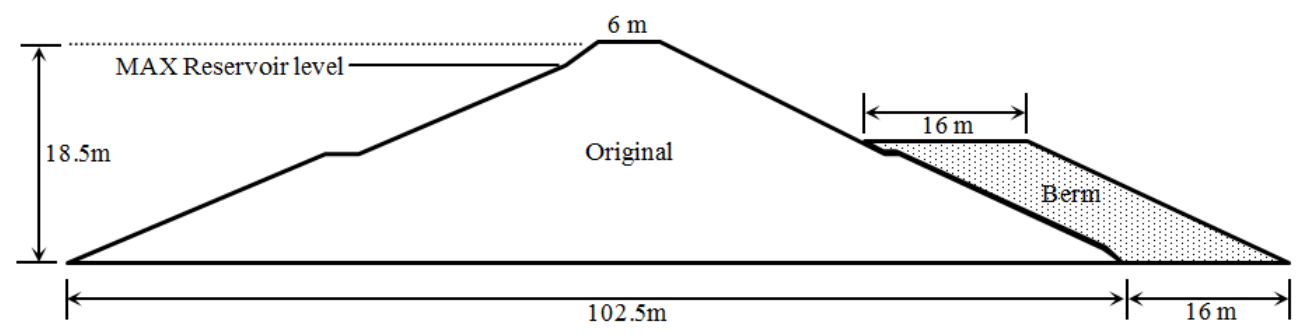

Fig.6 Strengthening model 1, S1

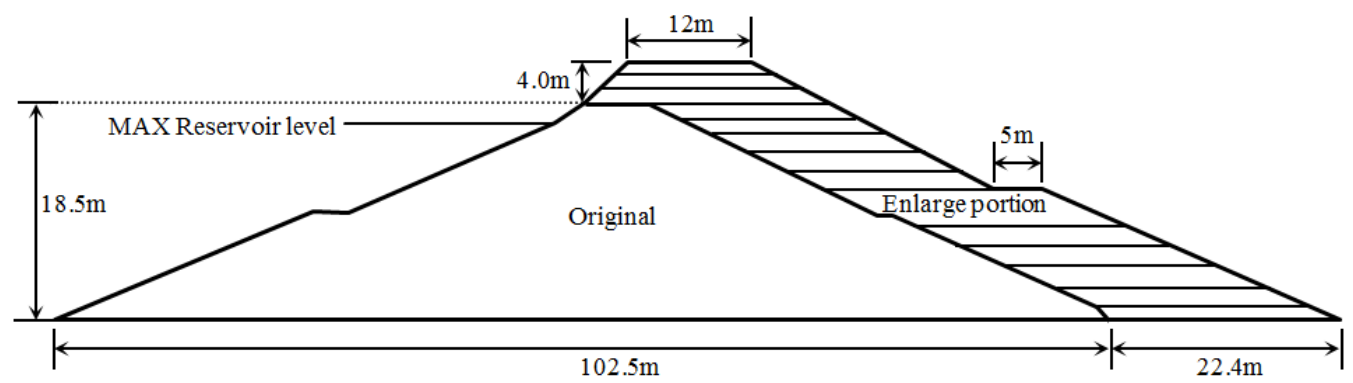

Fig.7 Strengthening model 2, S2

berm (hereafter, S2). The S2 model is shown in Fig.7. The actual dam was enlarged by increasing the crest height by $4.0 \mathrm{~m}$, doubling the crest width, and adding a downstream berm, which made the total added soil volume about $40 \%$ of the original dam volume. 3) Add geogrid reinforcement to the dam (hereafter, S3). Some modifications were made. Geogrids were applied in the dam body with $3 \mathrm{~m}$ spacing between each layer from the bottom to the crest that resulted in a total of 7 geogrid layers (Fig. 4). The geogrid was modeled as a cable element, which is considered only the axial rigidity and can only resist tensile force. In all the strengthening models, the upper portions of the dam were replaced by the material applied in the middle portion of the dam, which was considered as one of the strengthening methods for this dam.

The purpose of this study is to determine the failure mechanisms of the Fujinuma Dam and to introduce possible strengthening techniques. Therefore, the analysis can be divided into two parts. First, the actual and remaining dam models were analyzed to study the dynamic behavior of the dam and its failure. Second, dynamic analyses of all strengthening models were conducted. The results for all cases are then discussed and compared.

As the purpose of this study is to determine the failure mechanisms of the Fujinuma Dam and to 
introduce its possible strengthening techniques. Therefore, the analysis can be divided into two parts; first, the actual and remaining dam models were analyzed to study on the dynamic behavior and its failure; and the dynamic analyses of all strengthening models were conducted. The results for all cases were then discussed and compared.

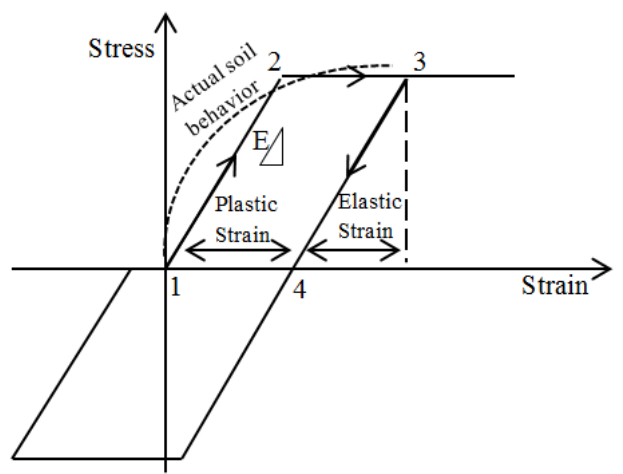

Fig.8 Cyclic behavior using elastic-perfectly plastic model

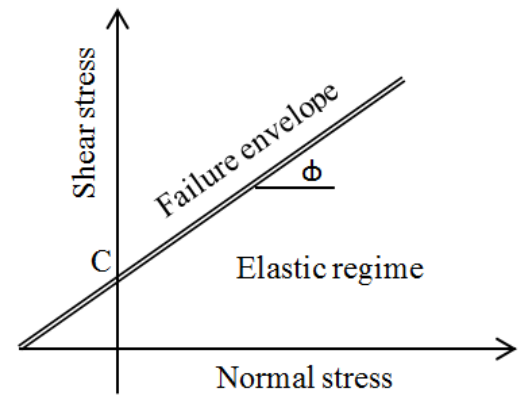

Fig.9 Mohr-Coulomb failure envelope

\section{(2) Constitutive law}

Soil behavior is nonlinear, and to precisely reproduce the stress-strain relationship during dynamic load, the advanced constitutive law and finite element formulation at a large deformation are required. However, the simple elastic-perfectly plastic constitutive model was applied widely in this field of practice. Therefore, the soil behavior in this study is described using the Mohr-Coulomb model. In addition, recommendations and limitations on the use of this constitutive law in the field of analyzing the earth dam are provided. The behavior of the dam materials is described using the Mohr-Coulomb soil model, which is an elastic-perfectly plastic model with a yield surface in which elastic behavior is defined by isotropic elasticity through a linear Young's modulus $E$. The model has yield surfaces defined by cohesion $c$ and friction angle $\phi$. The generalization of the Coulomb friction failure law is then defined by

$$
\tau=\sigma_{n} \tan \phi+c
$$

In which $\tau$ is the magnitude of the shearing stress, $\sigma_{n}$ is the normal stress, $c$ is cohesion, and $\phi$ is the angle of internal friction.

The associate plastic flow rule was used in this study, in which the dilatancy angle is indeed the same value as the friction of the angle, so the same surface is applied for the normalized plastic rule. Please note that the hardening and softening effect of soil is not included in this study.

The cyclic behavior of the simple elastic-perfectly plastic model is shown in Fig.8. It can be seen that for stress states that fall inside the yield surface or failure envelope in Fig.9, the behavior is elastic, and all strains are reversible as showed at points 1-2 in Fig.8. Thereafter, if the force was applied further to the system until it reached or exceeded the failure surface, the plastic strain or permanent strain that occurred is defined as points $2-3$ in Fig.8. At point 3, the total strain is now a summation of elastic and plastic strain. And if we unloaded the system, the elastic strain is then diminished and eventually vanishes, leaving only plastic strain when the system is at rest (Fig.8, 3-4). Similarly, when the system is reloaded, the behavior is repeated from 1-4 in Fig.8 as mentioned.

In dynamic analysis, the elastic behavior of this model does not include the hysteretic damping. To take into account the soil's damping characteristics, Rayleigh damping is applied. Also, when using the Mohr-Coulomb model (which is included in the plasticity model) when the failure surface is reached, the energy is subsequently dissipated though plastic deformation. However, when using the simple constitutive Mohr-Coulomb model, it must be noted that the complex dynamic soil behavior cannot be represented thoroughly. In particular, the strain dependent behavior of stiffness and damping cannot be modeled.

The parameters of the dam materials were obtained mainly from the laboratory experiments (as mentioned earlier in relation to Table 2), whereas the properties of the foundation and geogrid were assumed. The geogrid parameters were defined in terms of axial rigidity, EA, and tensile strength. Each parameter used in the analysis was described as mentioned earlier.

\section{RESULTS AND DISCUSSIONS}

\section{(1) Modal analysis}

Modal analysis was conducted to get the fundamental natural frequency and its corresponding mode shape of the numerical models. As aforemen- 
tioned, five models are proposed in this study. First, to determine the failure of the dam, the actual dam model and the remains dam model were analyzed. In the lateral direction, the natural frequencies are 1.64 $\mathrm{Hz}$ and $2.35 \mathrm{~Hz}$ for the actual dam model and the remains dam model, respectively.

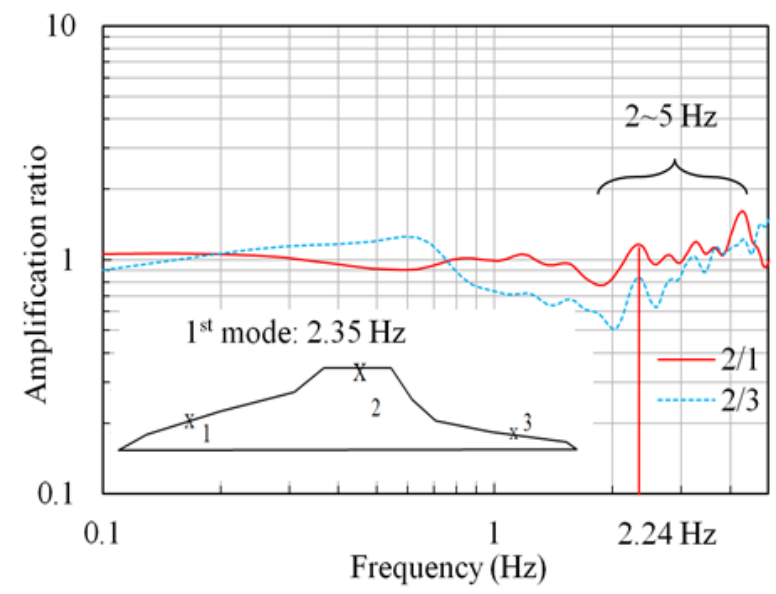

Fig.10 Amplification ratio

Fig.10 shows the amplification ratio that was taken from the top of the remains of the dam to two locations near the dam base of the upstream and downstream slopes, defined as $2 / 1$ and $2 / 3$, respectively. By comparing the numerical results with microtremor test results, it can be seen that in the latitudinal direction, the amplification ratio is within the range of $2-5 \mathrm{~Hz}$. The results obtained from the modal analysis of the dam remains agree well with field observations in relation to the vibration in the latitudinal direction. Therefore, the estimated predominant frequency of the original dam is $1.64 \mathrm{~Hz}$. Besides, in the lateral direction, the natural frequencies of all dam strengthening models are therefore $1.76 \mathrm{~Hz}, 1.40 \mathrm{~Hz}$, and $1.77 \mathrm{~Hz}$, respectively.

\section{2) Dynamic analysis}

A dynamic analysis was performed to determine the possible behavior of the dam during an earthquake. The results are expressed through acceleration, deformation, shear strain, and pore pressure.

\section{a) Acceleration}

The maximum crest acceleration is determined to be $7.42 \mathrm{~m} / \mathrm{s}^{2}$ and $7.60 \mathrm{~m} / \mathrm{s}^{2}$ accelerating towards the upstream direction at the time of $104.45 \mathrm{~s}$ and 72.78 $\mathrm{s}$ for the observed and simulated motions, respectively. The ratio of the maximum acceleration at the dam crest to the maximum acceleration at the dam base $(0.0 \mathrm{~m})$ was observed to determine the amplification effect of the dam body and its material. For both cases, it can be seen that the crest acceleration is amplified significantly. The maximum amplification ratio taken from the crest to the base is 1.76 and 1.79 for the observed and simulated motions, respectively. Also, the spectrum of the observed motion showed that it is characterized by a wideband. Hence, it might have induced resonance in the dam body and caused a higher response at the dam crest.

The observed motion contains high-amplitude waves for a longer duration than the simulated motion. This generates a great response throughout the dam body resulting from significant inertial force acting on the dam. This causes a great amount of plastic deformation and eventually dam failure owing to the loss of freeboard. In contrast, the simulated motion contains high-amplitude waves only for a comparatively short period; thus, this does not contribute a sufficient effect to cause large displacement of the dam.

For the strengthening models, all cases were analyzed by using the simulated motion. The summaries of the crest acceleration with its direction and the maximum crest to base amplification ratio are shown in Table 3. The results show that the maximum crest acceleration can be seen from $\mathrm{S} 1$, which is determined to be $9.63 \mathrm{~m} / \mathrm{s}^{2}$ accelerating towards the upstream direction. The lowest maximum crest acceleration belongs to $\mathrm{S} 3$, that is, about $8.48 \mathrm{~m} / \mathrm{s}^{2}$ acting toward the upstream side. For all cases, it can be seen that the crest acceleration is obviously amplified. The highest maximum amplification ratio taken from the crest to the base is 2.20 , whereas the lowest is 2.0 using S1 and S3, respectively.

The results show that the actual dam model is less sensitive to excitation than the reinforced dam models. This is due to the higher rigidity provided in the retrofit models and the fact that the actual model could easily displace and dissipate the energy from the earthquake excitation.

Table 3 Acceleration

\begin{tabular}{|l|cccc|}
\hline Model & Actual & S1 & S2 & S3 \\
\hline $\begin{array}{l}\text { Crest } \\
\text { Acceleration }\left(\mathrm{m} / \mathrm{s}^{2}\right)\end{array}$ & 7.60 & 9.63 & 8.80 & 8.48 \\
$\begin{array}{l}\text { Direction } \\
\text { Upstream, U) } \\
\text { (Downstream, D) } \\
\text { Amplification ratio }\end{array}$ & $\mathrm{U}$ & $\mathrm{U}$ & $\mathrm{D}$ & $\mathrm{U}$ \\
\hline
\end{tabular}

\section{b) Deformation}

Deformation can be used as an index for judging the safety of the dam due to freeboard loss. The results are expressed through the crest displacement during the excitation.

Fig.11 shows the deformed mesh at $104.19 \mathrm{~s}$ and its corresponding displacement curves when subjected to the observed motion. It can be seen that the 
entire dam body was moved in the downstream direction. As time increased, plastic deformations were accumulated. This caused the permanent horizontal displacement Ux of $2.95 \mathrm{~m}$, and crest settlement Uy reached $1.80 \mathrm{~m}$ at $104.19 \mathrm{~s}$; this is considered as the point of dam failure due to the loss of freeboard. Settlements at other observation points yield a similar tendency, but the settlements were less with decreasing dam height.

Deformation in both directions at the end of the shaking using simulated motion and the actual dam model was $0.30 \mathrm{~m}$ and $0.65 \mathrm{~m}$ for the horizontal displacement and crest's settlement, respectively.

In the case of strengthening models, the permanent horizontal displacement at the dam crest was $0.57,0.005$, and $0.47 \mathrm{~m}$ for the strengthening models 1,2 , and 3, respectively. And, the settlement at the dam crest obtained using the strengthening models 1 , 2, and 3, was $0.49,0.19$ and $0.39 \mathrm{~m}$, respectively. As a result, by considering overtopping failure, all models were able to safely withstand the simulated motion. However, the uncertainty in the numerical analysis and the material model together with the previous study on the performance of an earth-filled dam based on the performance based design concept $^{7)}$ suggests that the safety factor of 2.0 should be taken into account. Accordingly, it is recommended that the settlement of the crest should not exceed 1.0 $\mathrm{m}$, so the allowable settlement should be limited to $0.5 \mathrm{~m}$. Therefore, all retrofit cases should be able to satisfy this criterion.

According to the facts, the dam experienced overflow subsequent to the dam breach. The one possible cause is that the significant settlement of the dam body led to the loss of freeboard. Although the results obtained from the actual dam model did not cause the loss of freeboard, the settlement is high, especially in the upper portion of the dam due to its softness.

The summaries of deformation using all models are shown in Table 4. By comparing the actual dam model and the strengthening models, we see that the minimum crest settlement was obtained from the $\mathrm{S} 2$, which is a $70.1 \%$ drop from the actual model.

\section{c) Shear strain}

Shear strain provides information for understanding the locations within the dam body that might be damaged severely during earthquake excitation.

Shear strain contours of the actual dam model when subjected to the simulated motion at various times are shown in Fig.12. A similar trend can be observed for both motions. Most of the dam body experienced an insignificant rate of shear strain. It can be seen that initially, large shear strains occurred in the upper portion, especially on the upstream side. Thereafter, occurrences of large shear strain can be observed clearly on both sides of the dam in the middle and bottom portions of the downstream slope. This excessive level of shear strain may indicate a possible cause for the dam failure.

Similarly, the sequence of dam failure has been reported by previous researchers ${ }^{13), 18), 19)}$ indicating that initially the dam experienced excessive deformation or a slide on the upper portion of the upstream slope. This, together with a subsequent large slide that occurred on the downstream face, yielded a loss of freeboard and triggered the overflow that resulted in the breaching of the dam. Therefore, we observe that the numerical results show good agreement with this scenario.

Many ${ }^{20-22)}$ indicated that the upstream and downstream may have their lowest factor of safety at different stages. Generally, the upstream slope is critical at the end of construction or after the rapid

Table 4 Deformation

\begin{tabular}{|l|l|cccc|}
\hline Model & Actual & S1 & S2 & S3 \\
\hline \multicolumn{2}{|l|}{ Crest Deformation $(\mathrm{m})$} \\
\cline { 1 - 2 } Direction & $\mathrm{Ux}$ & 0.30 & 0.57 & 0.005 & 0.47 \\
& $\mathrm{Uy}$ & -0.65 & -0.49 & -0.19 & -0.39 \\
\cline { 1 - 1 } & $\mathrm{Ux}$ & - & 90.4 & 98.3 & 38.3 \\
different & $\mathrm{Uy}$ & - & 24.2 & 70.1 & 53.7 \\
\hline
\end{tabular}

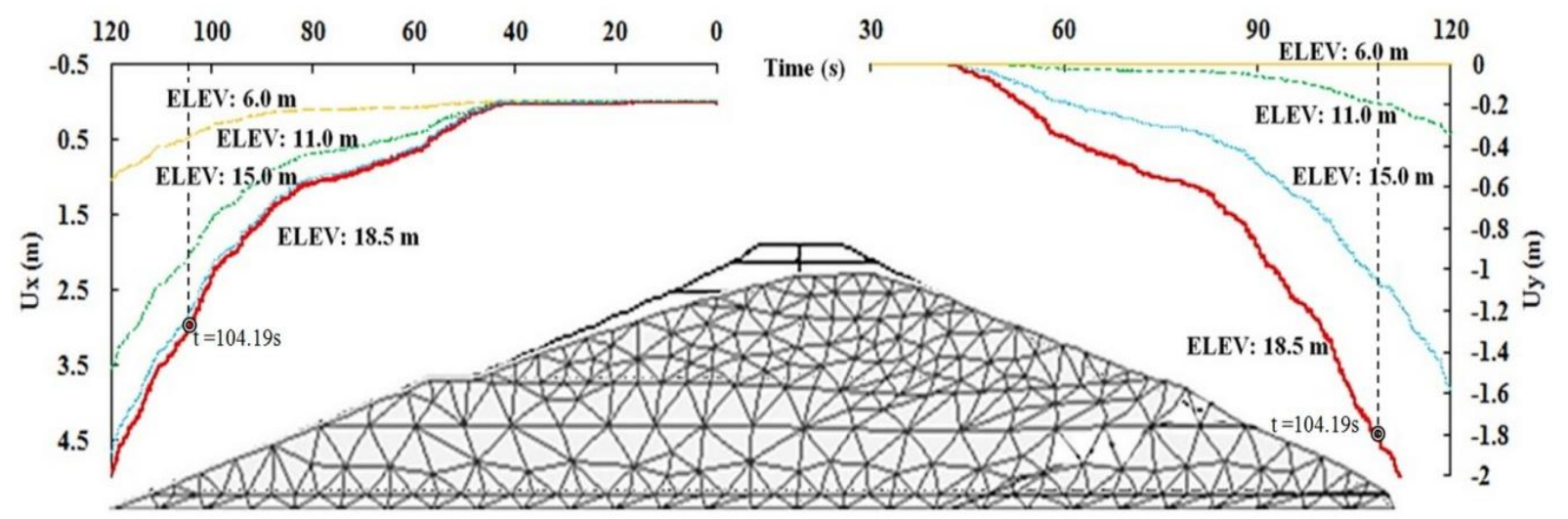

Fig.11 Actual dam model 
drawdown. When the reservoir is at the maximum storage level, a sudden drawdown takes place to the low level; this causes the upstream slope, which is now saturated, to become unstable. Therefore, this rapid drawdown causes the sliding failure of the upstream slope. In contrast, for the downstream slope, the critical condition is when the reservoir is full and the top of the phreatic line is at the highest level. The direction of the seepage force tends to decrease stability. The pore pressure acting on the soil mass below the phreatic line reduces the effective stress, thus resulting in the decrease of shear resistance, which causes the sliding of the downstream slope. In this study, the reservoir is at the maximum level, thus, the numerical results agree quite well with this assumption.

Shear strain contours at the end of the excitation obtained from the strengthening models S1 and S2 are shown in Fig.13. Also, Shear strain contours of S3 for various times are shown in Fig.14. Similarly, the same trend can be seen in all strengthening models, but it occurs in smaller values, and shear strain at the top portion appears to vanish. By comparing the actual dam model with all strengthening models, we can conclude that the maximum value of shear strain obtained from dam strengthening models greatly dropped by using S2 and S3. Therefore,
Some of the proposed methods seem to be effective measures for strengthening this structure, particularly by effectively solving the problem of large shear strain at the top portion.

\section{d) Excess pore pressure}

The distribution of the excess pore pressure within the dam body at $104.19 \mathrm{~s}$ and the records of the observation points A and B using the observed motion are shown in Fig.15. It can be seen that the excess pore pressure developed mostly at the downstream side. The maximum excess pore pressure was about $90 \mathrm{kPa}$, which can be found at the dam's base close to the dam center line. The suction or the positive excess pore pressure can be found on the upstream side. Based on the records of the excess pore pressure at observation points $\mathrm{A}$ and $\mathrm{B}$, we observe that the buildup in pore pressure fluctuated during the early period of shaking and then remained constant until the end of the excitation. The maximum excess pore pressures obtained from observation points $\mathrm{A}$ and $\mathrm{B}$ were about $48 \mathrm{kPa}$ and $18 \mathrm{kPa}$, respectively.

Similar trends were obtained for the simulated motion. The excess pore pressure was found to be scattered within the dam body. The upstream side experienced a pore pressure buildup of about 20-40 $\mathrm{kPa}$, whereas the downstream side gained greater values of excess pore pressure, especially at the
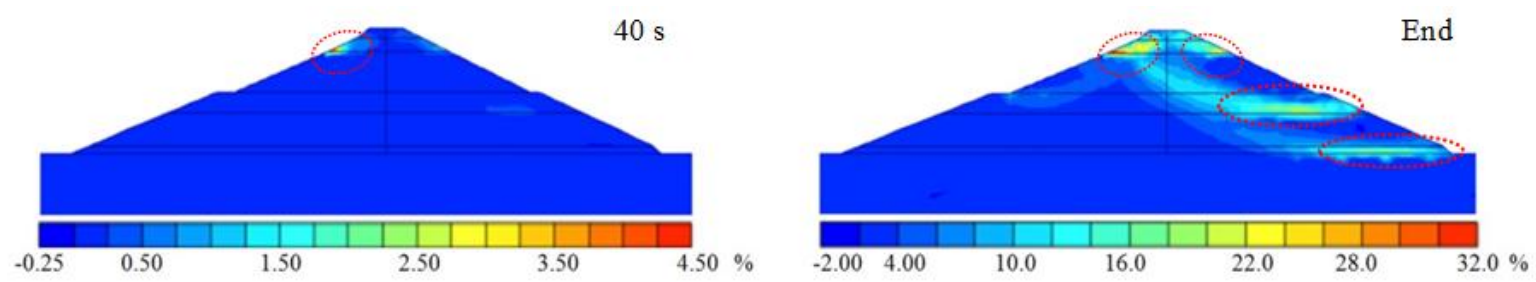

Fig.12 Shear strain contours at $40 \mathrm{~s}$ and at the end of motion using the simulated motion (actual dam model)

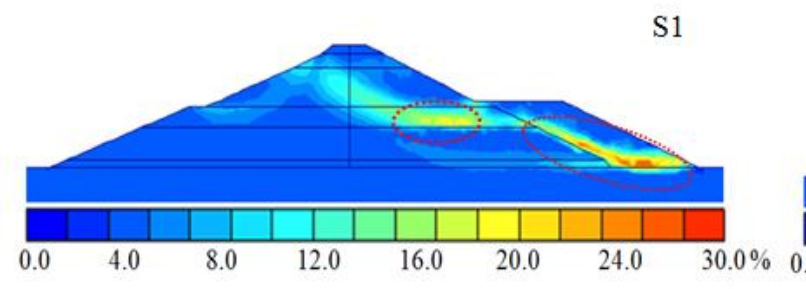

(a)

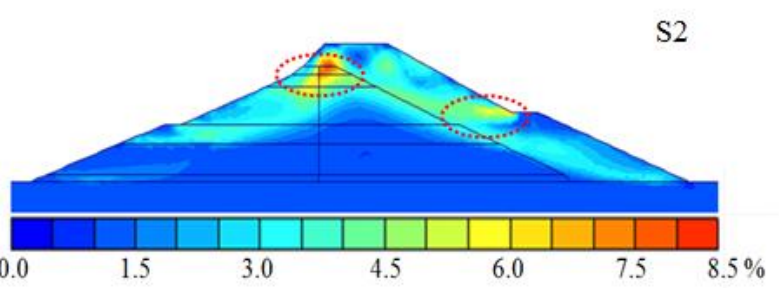

(b)

Fig.13 Shear strain contours at the end of motion using the simulated motion. (a) S1. (b) S2.
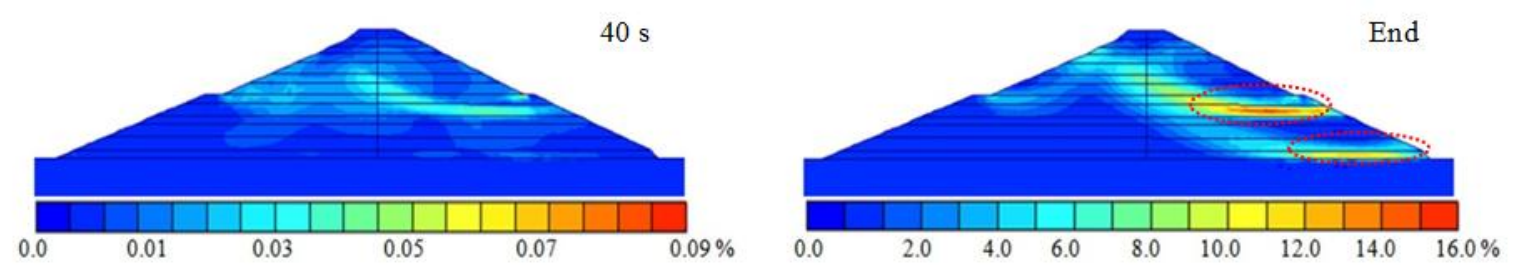

Fig.14 Shear strain contours at $40 \mathrm{~s}$ and at the end of motion using the simulated motion (S3) 


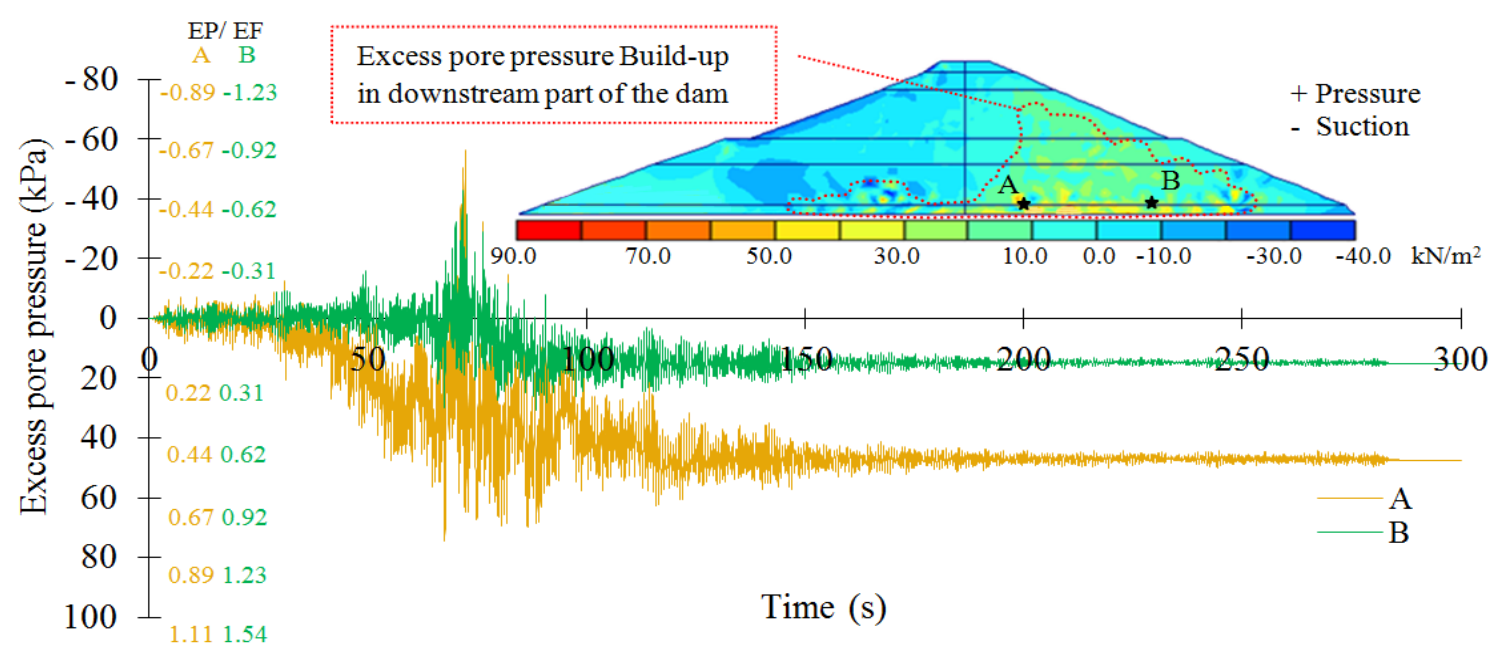

Fig.15 Excess pore pressure (actual dam model, using the observed motion)

lower portion of the dam. The maximum excess pore pressure was about $80 \mathrm{kPa}$ for the simulated motion. The results show that most of the dam body experienced a buildup in pore pressure that was not high enough to equal the effective stress and trigger the total loss of the soil strength. The maximum ratio taken from the excess pore pressure to initial effective stress (EP/EF) was 0.9; this was found in some parts within the downstream side, whereas most of the dam's body gained an insignificant ratio. However, in particular locations - such as on the downstream side, where the effective stress was found to be small - the reduction of shear strength can be fairly high and lead to significant permanent deformation in those areas.

For strengthening models, the maximum excess pore pressure was about $50 \mathrm{kPa}$ for $\mathrm{S} 1$ and $\mathrm{S} 2$ and 70 $\mathrm{kPa}$ for $\mathrm{S} 3$. The results show that most of the dam body experienced a buildup in pore pressure that was not high enough to equal the effective stress and trigger the total loss of the soil strength. The maximum ratio taken from the excess pore pressure to initial effective stress $(\mathrm{EP} / \mathrm{EF})$ was 0.9 for $\mathrm{S} 1$ and $\mathrm{S} 3$ and 0.8 for the S3. This maximum ratio can be found in some parts within the downstream side, whereas most of the dam's body gained an insignificant ratio. However, in particular locations - such as on the lower portion of the dam, where the effective stress was found to be small-the reduction of shear strength can be fairly high and lead to significant permanent deformation in those areas.

By comparing to the actual dam model, it can be seen that all retrofit models gave a slightly lower value for the buildup in pore pressure. Even though only a light reduction of pore pressure buildup can be obtained using these techniques, S1 and S2 gained a higher effective stress through the weight of their additional portion. The results enable us to get a better understanding of the effects of pore pressure. From this study, we found that another effective method to enhance the studied dam's resistance is to reduce the pore pressure and the dam's phreatic line (For example, reduced reservoir level, zoned type dam, grouting, drain filter, etc.).

\section{CONCLUSIONS}

This study aimed to understand the dynamic behavior and possible failure mechanisms of earth dams. The Fujinuma Dam, which failed after the 2011 Tohoku Earthquake, was selected for use as a model in this study. The study of the Fujinuma Dam includes the dam's dynamic behaviors, failure mechanism, and possible strengthening methods.

In this study, microtremor observations were conducted to discover the natural frequencies of the original dam and the remaining portion of the dam. By considering the application ratio taken from the crest to the base of the dam, we observe that the natural frequency of the dam remains obtained from numerical simulation showed a good agreement with the microtremor test results. Therefore, the same analysis's parameters were used for determining the natural frequency of the actual dam model.

When subjected to the observed motion, the dynamic analysis results of the actual dam model showed that the entire dam body was moved in the downstream direction, and large plastic deformations were accumulated. This caused crest settlement to reach $1.80 \mathrm{~m}$ at $104.19 \mathrm{~s}$, which is considered the point of dam failure due to the loss of freeboard. When the simulated motion was used, the settlement of the dam crest was $0.65 \mathrm{~m}$. When 
available freeboard length is considered, the dam seems to be safely withstanding the simulated motion. However, due to uncertainty in the numerical analysis and the material properties, previous researchers ${ }^{7)}$ suggested that the safety factor of 2.0 should be taken into account. Therefore, based on the performance of an earth-filled dam, it is recommended that the settlement of the crest should not exceed $1.0 \mathrm{~m}$, so the allowable settlement should be limited to $0.5 \mathrm{~m}$. The actual dam model is not able to satisfy this criterion.

According to the numerical results of the actual dam model, the model experienced large shear strains. The large shear strains were initially observed in the upper portion of the upstream slope, followed by large shear strains beginning on the downstream side. These shear strains might indicate the cause of the sliding failure of the dam slope and might trigger the overtopping of the dam. In addition, these sliding patterns exhibit good agreement with the facts gathered from field observations.

The results show that most of the dam body experienced a buildup in pore pressure that was not high enough to equal the effective stress and trigger the total loss of the soil strength. The maximum excess pore pressure can be found in some parts within the downstream side, whereas most of the dam's body gained insignificant value. However, in particular locations - such as on the downstream side, where the effective stress was found to be small - the reduction of shear strength can be fairly high and lead to significant permanent deformation in those areas.

Three strengthening techniques have been introduced in this study. These methods were proposed in order to discover suitable methods for strengthening the existing dam that could possibly be applied in similar cases to prevent dam failure. These strengthening methods are as follows: 1) S1, add downstream berm by half of the dam's height; 2 ) S2, enlarge dam and increase dam height; 3) S3, apply geogrid reinforcement layers. All strengthening models were analyzed using the simulated motion because it is difficult to compare the results using the observed motion.

The results clearly indicate that S2 and S3 seem to be effective measures for reducing the risk of the failure of this studied dam. S2 was found to be the most effective way to strengthen the dam-especially in the case of the existing dam due to its simplicity - and also because the crest settlement was found to be the smallest among the techniques. By raising the dam height and adding downstream berm, this strengthening method could safely resist the simulated motion. S3 (the geogrid reinforced model) was also found to be a good measure because it could reduce the crest settlement as well as the shear strain, which is much smaller than that observed in the actual dam model. However, in the case of the existing dam, S2 was found to be more appropriate because it is quite simple to use on an existing dam, whereas the geogrid reinforcement seems to be suitable for constructing a new dam.

In addition, a rough cost estimation of each technique was performed. Although this study gave a rough estimation due to lack of information, it is possible to find out the most suitable choice. The initial construction costs - such as initial planning, facilities, design, transportation, and equipment - are not included in this study.

For S1 and S2, the additional portions are about $20 \%$ and $40 \%$ of the original dam volume, respectively. To determine the required amount of soil volume, a swelling and compacting factor of 0.2 was used. To merge the additional portion to the original dam in this study, $20 \%$ of the original dam body was removed and refilled to provide good contact between the new and old portion. Based on information available online ${ }^{23)}$, the excavation price is 500 yen $/ \mathrm{m}^{3}$, and the backfill-compaction price is 1000 yen $/ \mathrm{m}^{3}$. Therefore, the costs of S1 and S2 are about 70.0 million yen and 105.0 million yen, respectively. $\mathrm{S} 2$ is more expensive than $\mathrm{S} 1$, but it improves the seismic resistance of the dam far better than S1, which narrowly passes the performance based design concept .

For S3, the cost of the geogrid and its installation is about 600 yen $/ \mathrm{m}^{2} .{ }^{23)}$ Assuming that the dam has the uniform cross-section along its length, S3 requires a total geogrid area of about $50,000 \mathrm{~m}^{2}$. Hence, $S 3$ costs about 30 million yen. However, due to the difficulties when S3 is applied to an existing dam, it seems to be inapplicable. However, it can be a good option for enhancing the capacity of a new dam during construction.

Thus, we conclude that the most appropriate method in this study is $\mathrm{S} 2$, because it provides a desirable seismic resistance and simple construction procedure at a rational cost.

The strengthening techniques proposed in this study mainly focused on structural content and rough cost estimation. Yet, the best solution needs to take into account many other factors-such as workability, the economic importance of the dam, and the effects on the downstream site- to select the most suitable method for each case. Therefore, where compromises between the strengthening method, 
cost, and the acceptable damage level could be met, other measures such as early planning, establishing an inundation map, making evacuation plans, or even "no action" might be considered possible mitigation strategies for this dam as well.

Through this study, it can be seen that there is always a risk for people who live near the dam site, especially on the downstream side. The Fujinuma Dam was constructed before the modern seismic design was established. Also, no seismic safety evaluation of this dam was conducted using state of the art techniques. Although this study presents only one case, there are still numerous earth-filled dams that need to be evaluated for seismic safety to ensure the safety of people and their property. Therefore, the seismic safety evaluation of existing dams is crucial and urgent. Otherwise, when future earthquakes strike, they may bring about a disaster to those who live downstream. This study demonstrates that it is very important to design a dam that is capable of withstanding future earthquakes. In addition, the investigation, maintenance, and damage mitigation of existing dams are vital for seismic safety.

ACKNOWLEDGMENT: The authors would like to acknowledge the contributions of the National Research Institute for Earth Science and Disaster Prevention for providing invaluable information. Special thanks are extended to Dr. Yoshiya Hata, Prof. Susumu Nakamura, and Dr. Atsushi Nozu for providing the ground motion used in this study. The authors would also like to thanks both Prof. Mamoru Mimura, Prof. Susumu Iai and staffs of the laboratory of Geo-disaster Division, Disaster Prevention Research Institute, Kyoto University, Japan, for their supports.

\section{REFERENCES}

1) Woodward, P. K. and Griffiths, D. V. : Influence of viscous damping in the dynamic analysis of an earth dam using simple constitutive models, J. Computers and Geotechnics., Vol. 19, No. 3, pp. 245-263, 1995.

2) Li, C., Borja, R. I. and Regueiro, R. A. : Dynamics of porous media at finite strain, Computation Methods in Applied Mechanics and Engineering, Vol. 193, pp. 3837-3870, 2004.

3) Rampello, S., Cascone, E. and Grosso, N. : Evaluation of the seismic response of a homogeneous earth dam, J. Soil Dynamics and Earthquake Engineering, Vol. 29 ,pp. 782-798, 2009.

4) Fallah, H. and Wieland, M. : Evaluation of Earthquake Safety of Koman Concrete Face Rockfill Dam in Albania, Proc. of 3rd Asian Conference on the Earthquake Engineering, ACEE, Bangkok, Thailand, 2010.

5) Perlea, V., Mathews, D. and Empson, W. : Evaluation of alternatives for earthquake hazard mitigation of an embankment dam in Kansas, Proc. of 13th world conference on earthquake engineering, Vancouver, B.C., Canada, August 1-6 paper number 1895, 2004.

6) Fade, M., Yazdani, M. and Azad, A. : Seismic retrofit of embankment dams based on dynamic nonlinear analyses, Proc. of 12th international conference of international association for computer methods and advances in geomechanics(IACMAG), October 1-6, Goa, India, 2008.

7) Tani, S., Tsukuni, S. and Shiomi, T. : Performance of a fill dam based on the performance-based design concept and study of a seismic retrofitting method, J. Soils and foundations, Vol. 49, No. 6, pp. 841-851, 2009.

8) Wulandari, P. S. and Tjandra, D. : Determination of optimum tensile strength of geogrid reinforced embankment, Proc. of International Civil Engineering Conference "Towards Sustainable Civil Engineering Practice", Surabaya, August 25-26, 2006.

9) Moradi, G., Abdolmaleki, A., Ahmadvand, M. and Ghadami, H. : Stabilization of rock slopes using geosynthetic materials as new approach and its comparison with conventional methods, Proc. of International symposium on advances in science and technology, Bandar-abbas, Iran, 2013.

10) Brinkgreve, R. B. J. and Vermeer, P. A. : Plaxis ver. 7, Material models manual, Balkema, Rotterdam, 1998.

11) Wikipedia. [Online]. Available: /http://en.wikipedia.org /wiki/Fujinuma_Dam. [Accessed Jan. 7, 2012]

12) Japan port and Harbor Association. : Technical standards for port and harbor facilities in Japan, pp. 281-288, 1999.

13) Tanaka, T., Tatsuoka, F., Mohri, Y. : Earthquake Induced failure of Fujinuma Dam, Proc. of International symposium on dams for a changing world, ICOLD, Kyoto, Japan, Vol. 6, pp. 47-52. 2012.

14) Andrews, D. C. A. and Martin, G. R. : Criteria for liquefaction of silty soils, Proc. of the 12th World Conference on Earthquake Engineering, New Zealand, 2000.

15) Japan Meteorological Agency (JMA). [Online]. Available: /http://www.jma.go.jp/en/quake/ [Accessed July. 7,2012]

16) National Research Institute for Earth Science and Disaster Prevention (NIED). [Online]. Available: /http://www.kyoshin.bosai.go.jp. [Accessed Jan. 6. 2012]

17) Hata, Y., Nakamura, S. and Nozu, A. : Seismic waveform evaluation at the Fujinuma Dam for the 2011 off the Pacific coast of Tohoku Earthquake-Application of site effect substitution method to a huge subduction earthquake, $J$. Structural Engineering, Vol. 58A, JSCE , pp. 250-263, 2011.

18) Harder, L. F. Jr., Kelson, K. I., Kishida, T., Kayen, R. : Preliminary Observations of the Fujinuma dam failure following the March 11, 2011 Tohoku Offshore Earthquake, Japan, Geotechnical reconnaissance of the 2011 Tohoku Japan Earthquake, GEER Association 25e, 2011.

19) Ono, K., Kazama, S., Kawagoe, S., Yokoo, Y., Gunawardhana, L. : Possible earthen dam failure mechanisms of Fujinuma reservoir due to the Great East Japan Earthquake of 2011, Hydrological Research Letters 5 (2011), pp. 69-72, 2011.

20) Sharma, R.K., Sharma, T.K., Irrigation Engineering, S. Chand \& Company Ltd, New Delhi, 2007.

21) Das, M. M., Saikia, M. D., Irrigation and Water Power Engineering, PHI Learning Pvt. Ltd, New Delhi, 2009.

22) Chowdhury, R., Flentje, P., Bhattacharya, G., Geotechnical Slope Analysis, CRC Press, 2009.

23) Free construction cost data. [Online]. Available: /http://www.allcostdata.info. [Accessed Feb. 2, 2015]

(2014.11.6 Received, 2015.2.12 Revised, 2015.2.21 Accepted) 